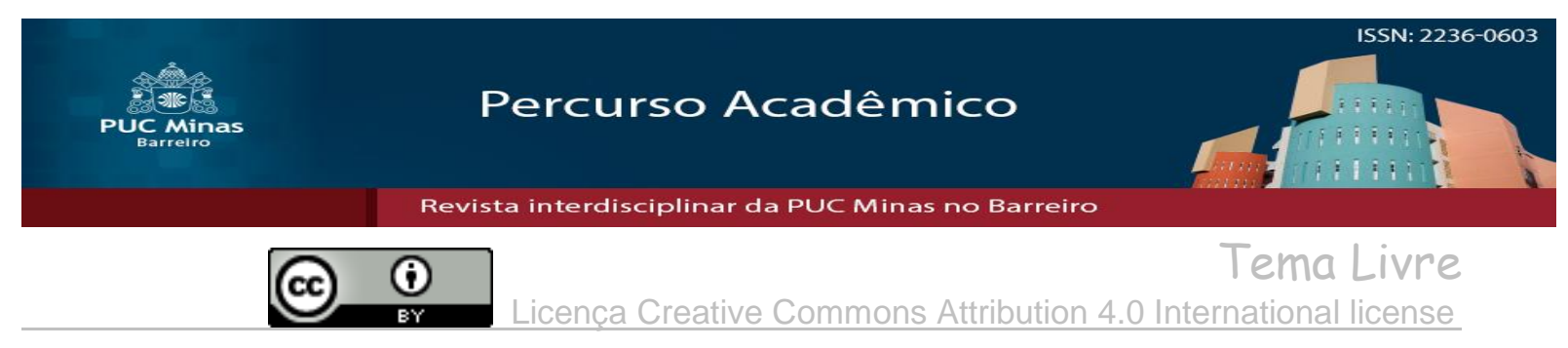

\title{
A eutanásia e o direito de escolha do paciente
}

\section{Eutanasia and the right of patient choice}

\author{
Murilo Aparecido Andrade Lugo ${ }^{1}$ \\ Karine Cordazzo ${ }^{2}$
}

\begin{abstract}
RESUMO
A Eutanásia em sua tradução literal significa boa morte, tratando-se de um tema muito discutido na sociedade atual. Muitos acreditam que seja um ato de misericórdia para com o paciente que esteja sofrendo, outros que seria um crime contra a vida. A proposta do presente trabalho é retratar o instituto da eutanásia, mais precisamente uma abordagem no tocante ao direito à prática da eutanásia. Abordar-se-á, a atual legislação e o anteprojeto (Projeto de Lei no 236/12) do Código Penal, que tipifica autonomamente a Eutanásia, por ser essa uma conduta revestida de sensibilidade e piedade, mas que apresenta uma série de pontos controversos, polêmicas e dúvidas. Aborda em seu principal escopo o direito sobre a vida e sobre a morte, quando e quais direitos devem triunfar, e razões, favoráveis ou contrárias a aplicabilidade da eutanásia bem como aborda os conflitos constitucionais envolvendo a referida temática no Brasil. Além disso, apresenta-se um panorama dos países que foram pioneiros na legalização do instituto da Eutanásia, os motivos que os levaram a essa legalização, os resultados provenientes da tipificação da Eutanásia e como podem servir de exemplo para que outros países sigam o mesmo caminho.
\end{abstract}

\section{Palavras-chave: Eutanásia. Ortotanásia. Direito de Escolha.}

\begin{abstract}
Euthanasia in its literal translation means good death, a topic that is much discussed in today's society. Many believe it to be an act of mercy to the suffering patient, others to be a crime against life. The purpose of this paper is to portray the institute of euthanasia, more precisely an approach to the right to practice euthanasia. The current legislation and the preliminary draft (Bill No. 236/12) of the Penal Code, which autonomously typifies Euthanasia, will be addressed, as this is a conduct that is coated with sensitivity and piety, but which presents a number of controversial points., controversies and doubts. It addresses in its main scope the right to life and death, when and which rights should triumph, and reasons, favorable or contrary to the applicability of euthanasia, as well as addressing the constitutional conflicts involving this subject in Brazil. In addition, it gives an overview of the countries that pioneered the legalization of the Euthanasia Institute, the reasons that led to this legalization, the results from the typification of Euthanasia, and how they can serve as an example for other countries to follow the same path.
\end{abstract}

Keywords: Euthanasia. Orthothanasia. Right to choose.

\footnotetext{
Artigo recebido em 29 de abril de 2019 e aprovado em 04 de dezembro de 2019

${ }^{1}$ Acadêmico do curso de Direito do Centro Universitário da Grande Dourados (UNIGRAN). E-mail: murilocpo12@gmail.com.

${ }^{2}$ Mestre em Fronteiras e Direitos Humanos pelo Universidade Federal da Grande Dourados (UFGD). Docente do curso de Direito do Centro Universitário da Grande Dourados (UNIGRAN). E-mail: karine.cordazzo@unigran.br.
} 


\section{INTRODUÇÃO}

O presente trabalho pretende demonstrar a necessidade de se abordar a temática da Eutanásia, especificamente no tocante ao seu cabimento e aplicabilidade no direito brasileiro.

Notadamente, o referido instituto é objeto hoje de inúmeras controvérsias, afinal, quando se pretende defender o direito de escolha do paciente em estado terminal, impacta-se diretamente no denominado senso de piedade da sociedade, o que leva às mais acentuadas discussões, ora favoráveis, ora desfavoráveis à legalização da eutanásia.

Sobre esta temática, é possível verificar que a eutanásia é tratada no ramo do direito, mais especificamente na vertente do Biodireito, assim como envolve questões de medicina e também sociais e religiosas.

Apura-se também que na atualidade existem vários países que são a favor da realização da Eutanásia, alguns a qualquer tempo desde que este seja o desejo do paciente, outros apenas em casos isolados, onde não existam chances de cura para o doente e o mesmo sofre com dores tais que se mostram insuportáveis; e ainda os que não permitem a realização do ato da eutanásia sendo este expressamente proibido, como é o caso do Brasil. O instituto da eutanásia ainda não está tipificado no Código Penal brasileiro, existindo apenas um anteprojeto com o fim de regulamentar tal crime.

\section{BREVE EVOLUÇÃO HISTÓRICA DA EUTANÁSIA}

A Eutanásia definitivamente não é um tema recente, sendo que desde os tempos antigos existem diversos registros de sua pratica, como cita Sônia Maria Teixeira da Silva(2000, p.01), onde 400 anos a.C, em Atenas Platão já indagava sobre o sacrifício de velhos, fracos e inválidos sob o argumento de interesse do fortalecimento do bemestar e da economia coletiva.

A palavra eutanásia foi criada no século XVII pelo filósofo inglês Francis Bacon, quando escreveu, na sua obra "Historia vitae et mortis", como sendo tratamento mais adequado para as doenças incuráveis (SILVA, 2000, p.1). Deriva-se de duas palavras gregas: $e u$, que tem como significado bem ou boa, e thanásia, que equivale a 
morte. No sentido literal, a eutanásia significa Boa Morte, a morte tranqüila, a morte com piedade.

O termo foi utilizado inicialmente, para referir-se a morte provocada por médicos em pacientes em estágios terminais, com doenças que eram incuráveis ou de incerta cura que estivessem passando por terrível sofrimento.Assim, percebe-se que a eutanásia sempre foi uma prática existente no decorrer da história.

\section{DIVERSAS ESPÉCIES DE EUTANÁSIA}

\subsection{Mistanásia}

O conceito de mistanásia é descrito como uma morte miserável, que é realizada prematuramente ou fora da hora, implicando grande sofrimento ao enfermo. Diferentemente da eutanásia propriamente dita, que representa a denominada morte boa ou suave, a mistanásia tem o conceito de morte sofrida.

Na América Latina, de modo genérico, a forma mais comum de mistanásia é por omissão de socorro estrutural que atinge milhões de doentes durante sua vida inteira e não apenas nas fases avançadas e terminais de suas enfermidades.

\subsection{Distanásia}

A distanásia é um procedimento médico que visa prolongar a vida dos pacientes em estado terminal. Nesse sentido, Maria Helena Diniz, (2006, p.399) conceitua que se trata do prolongamento exacerbado da morte de um paciente ou um tratamento que se mostra sem utilidade para o mesmo visando não prolongar a vida, mas sim o processo de morte.

Ou seja, ocorre quando os meios utilizados para manter um paciente em estado terminal se mostram ineficazes e sem sentido, mantendo a pessoa em um estado de "semi-vida" prolongando assim sua dor e sofrimento.

De acordo com Pessini (2004, p. 201), a distanásia é a "obstinação terapêutica em que a tecnologia médica é usada para prolongar penosa e inutilmente o processo de 
agonizar e morrer". Assim, a distanásia pode levar a um quadro de indignidade da pessoa humana, por usar de métodos considerados inúteis ou ineficazes, e por tempo exagerado.

\subsection{Ortotanásia}

A ortotanásia é a terceira espécie de Eutanásia, e também é conhecida como paraeutanásia. Apóia-se na omissão de auxílio médico, levando o paciente a ter uma morte natural, que segue o curso natural da vida, não sendo utilizados procedimentos médicos artificiais para prolongar a vida do paciente, como por exemplo, a respiração por aparelhos.

A ortotanásia é realizada através de cuidados paliativos, que procuram manter a qualidade de vida do paciente e de sua família, em casos de doenças graves e incuráveis. Assim, a ortotanásia é vista como a morte natural pela qual todo ser humano irá passar, tendo como objetivo não antecipar ou adiar a morte, mas sim buscar a melhor maneira de passar por ela, mantendo a dignidade da pessoa que está doente.

O caso concreto mais conhecido de eutanásia/ortotanasia é o caso da americana Theresa Marie Schindler-Schiavo (Goldim, 2005), onde ocorreu uma longa batalha judicial para definir o destino de Terri como era conhecida, que vivia em estado vegetativo persistente há três anos decorrente de uma parada Cardíaca. Doze anos depois do inicio da batalha na justiça, foi deferido o pedido do marido de Terri e os aparelhos que faziam sua alimentação foram desligados.

Esse é um caso que teve muita repercussão mundialmente pelo tempo que durou (longos 15 anos) e pela grande comoção social tanto para que a vida de Terri fosse preservada tanto para que se encerrasse o sofrimento da mesma que já não tinha chances de cura.

\subsection{O suicídio assistido}

Outro instituto que se assemelha à eutanásia, mas tem previsão legal é o suicídio assistido, que tem sua prática tipificada no artigo 122 do $\mathrm{CP}$, onde o induzimento ou 
auxílio ao suicídio é penalizado em 2 a 6 anos se o suicídio for consumado, ou, se a tentativa de suicídio resultar em lesão corporal grave a pena será de 1 a 3 anos.

O termo é comumente utilizado como sinônimo de suicídio medicamente assistido, que conforme Roxana Cardoso Brasileiro Borges, (2007, p. 235), é o suicídio praticado com o auxílio de um médico, que de forma intencional, disponibiliza à pessoa meios idôneos e/ou informações que são necessárias para que se cometa o suicídio.

Segundo Mirabete (2008, p. 50) "o suicídio é a eliminação da própria vida ou mais precisamente, no dizer de Euclides C. Silveira, "é a deliberada destruição da própria vida."

Além disso, complementa ainda Borges, (2007, p. 235) que para que a ação de auxílio ao suicídio tenha o valor de eutanásia, é necessário que o paciente tenha solicitado a ajuda para morrer, diante do fracasso dos métodos terapêuticos e dos paliativos contra as dores.

Entende-se então que a vontade do paciente e o pedido expresso pela morte é requisito para que se configure o suicídio assistido, preservando a dignidade da pessoa humana considerando o fracasso dos métodos terapêuticos.

\section{A EUTANÁSIA NO BRASIL}

A eutanásia é um tema que gera muita discussão em todo o mundo, e não é diferente no Brasil. O Anteprojeto do Código Penal em estudo pela Comissão encarregada de realizar mudanças na Parte Especial do Código em vigor tem tratado da tipificação da Eutanásia e se é possível introduzir tal instituto no Brasil.

A descrição do dispositivo se encontra no artigo 122 do Projeto de Lei do Senado $\mathrm{n}^{\circ}$ 236, de2012, que é o anteprojeto do Código Penal ${ }^{3}$, sendo uma grande alteração de um dispositivo que anteriormente não tinha nenhuma previsão legal no ordenamento jurídico e que tem estado em contínuo conflito com o direito à vida.

O que tenta se mostrar com esse projeto de lei é que não há o porquê insistir em uma defesa exagerada do direto à vida, colocando em risco outros direitos também fundamentais, dando espaço para uma relativização desse direito.

\footnotetext{
${ }^{3}$ Art. 122. Matar, por piedade ou compaixão, paciente em estado terminal, imputável e maior, a seu pedido, para abreviar-lhe sofrimento físico insuportável em razão de doen
} 
No Brasil atualmente, a Eutanásia é crime, tratando-se de homicídio doloso que em face da motivação do agente pode ser alcançada a condição de homicídio privilegiado, apenas reduzindo sua pena.

\section{EUTANÁSIA NA EUROPA}

\subsection{Holanda}

Na Europa, a despenalização da eutanásia e o suicídio assistido foram logo cedo debatidos, sendo a experiência Holandesa ponto principal para sua legalização. Além da Holanda, a Bélgica também permite a eutanásia e o suicídio clinicamente assistido além de outros nos dias de hoje.

O código penal vigente em 1981, em seus artigos 293 e 294 tipificava a eutanásia como crime (GRIFFITHS, 2008, p. 30). Sua prática, no entanto, atingiu a legalidade por meio de uma jurisprudência (SMIES, 2003, p.4).

Devido as manifestações públicas sobre os casos que surgiam no pais, essa jurisprudência tornou mais branda as punições e edificou critérios para a realização da eutanásia.

No fim de 1984 a Suprema Corte abordou o assunto e reafirmou que a eutanásia é considerada crime na lei holandesa frente ao caso concreto Schoonhleim, porém, informou que quando médicos se vissem confrontados em conflitos de deveres, poderiam clamar pela defesa da necessidade (SMIES, 2003, p.23; GRIFFITHS, 2008, p. $31)$.

Um conflito de deveres nasce quando a obrigatoriedade ética de conceder o desejo do paciente para morrer com dignidade leva o médico a agir de maneira oposta às disposições do Código Penal (que é baseado no respeito à vida humana).

No mesmo ano, foi afirmado pelo Conselho Executivo da Sociedade Real Holandesa de Medicina a proibição da eutanásia, mas elucidando que em determinadas condições a prática seria aceitável.

Segundo Nicol et al. (2013, p.12) a Corte holandesa em 1995 recebeu dois casos de médicos que realizaram eutanásia em crianças que tinham incapacidade severa, 
doença grave que não tinha expectativa de ultrapassar o primeiro ano de vida. Nessas duas situações o médico havia praticado a ação em razão de pedido e requerimento dos pais. A Corte definiu então que os médicos haviam procedido de acordo com a boa prática médica.

Depois de muito debate, em 1999 foi criado um projeto de lei sobre a eutanásia no parlamento Holandês. No dia 28 de Novembro do ano de 2000 a lei foi finalmente aprovada em primeira instancia no parlamento por 104 votos a favor e 40 contra. Após, foi direcionada ao senado e em 10 de abril de 2001 foi aprovada por 46 votos favoráveis e 28 contras. Assim, depois de passar pelas duas câmaras de votação, a lei foi aprovada por meio de decreto no dia 15 de março de 2002, entrando em vigor no dia 01 de abril no mesmo ano (SMIES, 2003, p. 37).

Deve-se ressaltar que a eutanásia e o suicídio assistido são permitidos na Holanda em condições bem estritas, sendo que apenas médicos estão autorizados por vias legais a ministrar drogas letais para findar a vida de um paciente, tendo que ser atendidos os critérios do devido cuidado (FRANCKE, 2016, p.783).

Dessa forma, se consegue controlar quem fará e porque se adotará o procedimento, a condição clínica do paciente e sua expressa vontade.

\subsection{Bélgica}

Na Bélgica a legalização da eutanásia ocorreu após uma proibição expressa da prática assim como ocorreu na Holanda.

Em janeiro de 2000, foi votada no senado uma proposta de lei com tema eutanásico, onde a prática da eutanásia não iria mais ser punida desde que orientada por determinados procedimentos. A lei foi adotada em 20 de março de 2001 e a manifestação a favor do Comitê Consultivo Nacional de Bioética possibilitou passagem da lei pelo Parlamento em 16 de maio de 2002 com 86 votos a favor, 51 contra e 1 abstenção. Dessa forma, a lei da eutanásia promulgada em 28 de maio de 2002 e em vigor desde 23 de setembro de 2002 legalizou a eutanásia ativa. A prática foi definida como o ato de por fim de forma intencional à vida de outra pessoa a pedido desta. (GRIFFITHS et al., 2008, p.264). 
No início, a aplicação de tal lei na Bélgica foi mais rígida do que na Holanda, pois não permitia que a eutanásia fosse realizada em menores de dezoito anos. Por outro lado, a mesma lei permitia a eutanásia em pessoas que não estavam em fase de término da vida. Por razão do aumento da quantidade jovens que passaram a requerer a eutanásia, em fevereiro de 2014 a lei sofreu uma emenda e o país passou a autorizar a eutanásia em pessoas de qualquer idade, mas para todos os casos, restrita somente aos pacientes em estado terminal.

\section{O RECENTE CASO ESPANHOL}

Em Abril de 2019, um caso sobre a Eutanásia se tornou notícia no mundo. Ángel Hernández, um senhor Espanhol, ajudou sua esposa María José Carrasco, que há 30 anos sofria de esclerose múltipla a cometer suicídio.(TROYA, 2019)

Relata que Maria José há muito lhe pedira que a ajudasse a encerrar seu sofrimento, causado por esses longos anos convivendo com a doença, estando já em estado terminal, onde estava trancada em um corpo que não podia mais se mover, com dificuldades para ouvir, ver, falar. (TROYA, 2019)

Não podendo mais se mover, seu marido foi as suas mãos, lhe dando de beber pentobarbital sódico. Ambos decidiram gravar o caso, permanecendo ela adormecida, não tendo sofrido como relata Hernández.(TROYA, 2019)

Hernández foi a primeira pessoa detida na Espanha por ajudar alguém que estava incapaz de tirar a própria vida. Porém já sabia desse desfecho, pois poderia ter feito o ato no anonimato, mas decidiu por gravar tudo para que o governo desse atenção para o tema da eutanásia. Fez isso pelas pessoas que ficam, pois existem muitas pessoas na mesma situação de sua esposa e que devido a lei não regulamentar a prática, vivem no sofrimento e dor. (TROYA, 2019)

Assim, termina relatando que vai continuar lutando para que uma lei que positive a prática da eutanásia seja criada, para que pessoas no mesmo estado que sua esposa se encontrava não precisem cometer o ato sem nenhuma supervisão médica. (TROYA, 2019) 
Vemos nesse caso que há muitas vertentes a serem analisadas quando falamos de eutanásia, tanto do ponto de vista médico quanto do jurídico, e sobre os bens jurídicos de maior relevância e que devem ser protegidos.

\section{PRINCÍPIOS FUNDAMENTAIS NA EUTANÁSIA}

\subsection{Princípio da dignidade da pessoa humana}

É um princípio de grandiosa importância, onde se apresenta pertinente e se encaixa perfeitamente na discussão sobre o tema, pois, relaciona as normas concernentes a autonomia e dignidade do indivíduo.

No Brasil, a dignidade da pessoa humana está tipificada na Constituição Federal, em seu artigo $1^{\circ}$, inciso III, dentre o rol dos Direitos Fundamentais. Sendo assim não se trata somente de um princípio fundamental previsto e garantido pela Constituição Federal, mas, possui uma valoração intrínseca ao ser humano e único para cada individuo, não podendo inclinar-se em favor de ninguém.

Na concepção de Luís Roberto Barroso (2013, p.72), atual ministro do Supremo Tribunal Federal a dignidade da pessoa humana identifica o valor intrínseco do ser humano, além da sua autonomia e é limitada por algumas restrições legitimas que são impostas à pessoa em nome de valores ou interesses estatais, e tem como um de seus papéis principais, o de funcionar como fonte de direitos e deveres.

De tal forma, a dignidade da pessoa humana atinge os diversos ramos do ordenamento jurídico, cumprindo inúmeras funções dentro do sistema jurídico social, tendo por isso um grau de abstração muito elevado, o que implica numa dificuldade no que diz respeito a sua delimitação e aplicação.

\subsection{Princípio do Direito à vida}

É certo que o princípio do Direito à vida é aquele que mais conflita com a prática da eutanásia, onde a mesma encontra sua proibição legal quando se depara com o direito à vida por este ser relevante, indisponível, inalienável e irrenunciável. 
Conforme os ensinamentos de Alexandre de Moraes (2002, p. 176), a vida tem um valor súpero com relação a todos os outros direitos, pois sem ela, o exercício e a própria existência dos demais direitos não terão sentido algum.É regido pelos princípios Constitucionais da inviolabilidade e irrenunciabilidade, ou seja, o direito à vida, sendo muito difícil ir contra ele, sendo possível até mesmo a responsabilidade criminal para quem desrespeita esse principio, com raras exceções.

Nesse sentido defende ainda Alexandre de Moraes (2000, p. 91) "o direito à vida tem um conteúdo de proteção positiva que impede configurá-lo como o direito de liberdade que inclua o direito à própria morte”.

Como garantia constitucional, o homem tem direito à vida e não direito sobre a vida, sendo responsabilidade do Estado garantir a proteção desse direito e proporcionar uma vida digna para a pessoa humana, dessa forma, como deve garantir a vida, proíbe a morte provocada, como a eutanásia.

Porém um ponto a se destacar é que, a eutanásia que Anteprojeto do Código Penal visa regulamentar pode não ser vista como uma ameaça ao direito à vida, uma vez que seria aplicada em indivíduos que estejam em um estado clínico irreversívele inevitável, em estado terminal, onde não mais esteja gozando plenamente de seu direito à vida, vivendo através de aparelhos por exemplo.

\section{COLISÃO DE PRINCÍPIOS FUNDAMENTAIS NA EUTANÁSIA}

Quando se aborda um caso eutanásico, o agente realizador se expõe a diversos princípios constitucionais, configurando um conflito entre as normas.

Sendo assim, para se discutir a aplicação da eutanásia é necessário a compreensão geral sobre o tema e suas acepções, sendo também necessário o conhecimento da dogmática envolvendo a colisão de princípios.

Ponderando sobre tal colisão, Robert Alexy (2012, p. 93-94) indaga que quando ocorre a colisão de dois princípio, um dos dois deverá ceder, não significando que aquele que cedeu será considerado inválido, mas sim que ele foi afastado em prol de um princípio com maior peso nesse caso específico. 
Ou seja, existindo a colisão entre dois princípios considerados fundamentais, deve-se analisar qual princípio deve ser aplicado no caso concreto, visando sempre o melhor para o doente.

Contudo, um princípio constitucionalmente garantido não é soberano ou perpétuo, tendo a possibilidade de ter sua aplicabilidade afastada de acordo com a necessidade do caso concreto.

Nessa mesma alínea, Maria de Fátima Freire de Sá (2001, p. 95) indaga ser inadmissível que o direito à vida, constitucionalmente garantido, transforme-se em dever de sofrimento e, por isso, dever de viver.

O Direito à vida é uma garantia constitucional expressamente prevista, mas não necessariamente o dever à vida a qualquer custo, para os que defendem a prática da eutanásia, não seria correto manter viva a pessoa que na realidade já não tem mais capacidade de viver dignamente, somente em função do princípio da inviolabilidade da vida, pois assim estaria ferindo o princípio da dignidade da pessoa humana.

Assim, os defensores da prática da eutanásia argumentam que a vontade do paciente que não tem mais perspectiva de melhora, representada pelo princípio da autonomia da vontade, deve ser respeitada.

Nesse pensamento, Rachel Sztajn (2006, p. 16) expõe que o consentimento informado é um requisito de validade, além de a pessoa ser capaz e manifestar sua vontade livre de morrer, assim respeitar-se-á a autonomia das pessoas e a liberdade individual.

Ainda no mesmo escopo, Maria Helena Diniz (2006, p. 16) explica que o princípio da autonomia requer que o profissional da saúde respeite a vontade do paciente, ou de seu representante, levando em conta, em certa medida, seus valores morais e crenças religiosas.

É de muita dificuldade em aspecto jurídico e até mesmo em aspecto médico definir até que ponto um paciente pode suportar as dores advindas de uma enfermidade, e mesmo que fosse estipulado um limite, esse limite não seria igual para todos os pacientes, pois só aquela pessoa que passa por essa dificuldade, poderia analisar até que ponto suportaria essa situação, por isso é um tema de difícil tipificação. 
Analisando essas alegações, é muito dificultoso colocar na balança o conflito entre manter a vida de uma pessoa a qualquer custo ou encerrar sua vida de uma maneira um pouco mais digna, lhe conferindo um período menor de sofrimento. Em um caso concreto, poderia ser interessante atender ao pedido do paciente, pois a dor é algo pessoal para cada pessoa, não cabendo a terceiros opinar se essa dor é ou não suportável, para que o princípio da autonomia da vontade que é assegurado constitucionalmente seja conferido a essa pessoa em seus últimos dias de vida.

Ainda nesse mesmo norte, Rachel Sztjan(2002 p.177) elucida que se conferido o direito a autonomia da vontade do paciente, todas as manifestações necessárias devem ser documentais ou estar devidamente documentadas, com todas informações prestadas pela equipe de saúde.

Ou seja, para que a autonomia da vontade seja efetivada, é necessário que tudo seja documentado, pois é necessário que essa vontade seja expressa e segura, não podendo pairar dúvidas sobre a real vontade do paciente.

Maria Helena Diniz (2011, p. 40-1) conceitua o princípio da autonomia da vontade como "o poder de estipular livremente, como melhor lhes convier, mediante acordo de vontade, a disciplina de seus interesses, suscitando efeitos tutelados pela ordem jurídica."

Então perante a uma situação de um paciente em estado terminal irreversível, onde nada mais poderia ser feito para reverter o seu quadro, atender o seu pedido nessa situação seria uma concretização da tutela de morrer com dignidade.

\section{A QUESTÃO JURÍDICA DA EUTANÁSIA NO DIREITO BRASILEIRO}

Como já mencionado anteriormente, no Brasil a execução da eutanásia em todas as suas formas é proibida, sendo que existe um anteprojeto no código penal com o objetivo de realizar alterações nas condutas hoje catalogadas como criminosas.

A legislação brasileira atual tem assegurado todos os direitos à vida, protegendoa desde a concepção até a morte e esse anteprojeto pretende tornar a legislação mais maleável no que se refere ao direito à vida. 
Existiu também o Projeto de Lei n. 125, de 1996 do Senado Federal, que foi uma tentativa de se inserir no Brasil uma maneira de encerrar a dor e o sofrimento do enfermo, e tinha seu enfoque a legalização da eutanásia.

O projeto propunha que a eutanásia fosse permitida desde que, um conjunto de cinco médicos, sendo dois deles especialistas no problema da pessoa, ateste a inutilidade do tratamento e o sofrimento físico ou psíquico do paciente, sendo que o pedido para a prática da eutanásia teria que ser feito pelo paciente, se este estivesse em um estado de inconsciência, a decisão caberia aos familiares próximos.

No código penal em vigência, a eutanásia é enquadrada como sendo homicídio praticado por relevante valor moral, considerado homicídio privilegiado, e está previsto no parágrafo $1^{\circ}$ do artigo 121 do $\mathrm{CP}$, com pena mais branda por ser cometido por relevante valor moral se comparado com o homicídio de fato.

Sobre o assunto, Mirabete (2007, p. 34) expõe que o valor moral expresso no $1^{\circ}$ parágrafo do artigo diz respeito aos sentimentos particulares do agente, tal como a piedade e a compaixão, não deixando de punir a eutanásia, mas permitindo a minoração da pena. Ou seja, é levado em consideração o sentimento de dever moral que a pessoa sentiu no momento, que a levou a cometer o ato de homicídio, assim aplicando uma causa de diminuição de pena em tal caso.

\section{ARGUMENTOS FAVORÁVEIS À EUTANÁSIA}

Em primeiro lugar, um dos fundamentos de maior utilização pelos que defendem a eutanásia consiste no respeito à autonomia da vontade do ser humano, como um direito decorrente dos direitos de liberdades. O respeito à autonomia do paciente significa possibilitá-lo para decidir, não apenas acerca da melhor terapia, mas, principalmente, sobre a sua vida e o momento da sua morte.

Para Maluf (2013, p. 439), “a eutanásia não defende a morte, mas uma escolha por parte de quem a entende como a melhor opção ou como a única opção possível. Desse modo, vida, em sua concepção, é inserção, e, nesse sentido, a denominada qualidade de vida que não pode ser transformada num demorado e penoso processo de morrer". 
No mesmo contexto, Passini (2004, p. 3) exclama que "o respeito à autonomia da pessoa levando em conta seus aspectos físicos, emocionais, sociais e espirituais, o amparo à família do doente e etc, permite que o doente possa enfrentar positivamente esses desafios que lhe são impostos no fim de sua vida".

Desse modo, o princípio da autonomia teria um peso maior em casos eutanásicos, pois se entende que o direito à vida deve ser considerado como uma obrigação do Estado, mas não uma imposição, sendo a questão da dignidade fator obrigatória para a manutenção da vida humana, até porque não existiria dignidade sem respeito à autonomia.

Nessa seara, devem ser registradas as observações de Junges (1999, p. 183) que indaga que em situaçõesdistanásicas, deve-se afirmar que não é necessário fazer, sempre e todas as circunstâncias, o máximo para conservar a vida de alguém, pois a existência meramente biológica não significa necessariamente vida humana.

Dessa forma, compreende-se então que a prática da eutanásia seria um caminho para que se diminua o sofrimento e a dor do enfermo e de seus familiares, principalmente encontrando-se ele em fase terminal, na falta absoluta de qualidade de vida. "A dor, sofrimento e o esgotamento do projeto de vida, são situações que levam as pessoas a desistirem de viver" (PINTO; SILVA, 2004, p. 36). Nessas situações, deve-se concluir que viver nessa situação seria pior do que morrer, pois a dor causada pela enfermidade terminal tornaria extremamente difícil a vida desse paciente, e o caminho da eutanásia pode ser um escape dessa dor, e ainda uma maneira mais digna e que encerraria a dor do paciente.

Nessa linha de pensamento, prolongar a dor e o sofrimento do enfermo sem que se tenha qualquer previsão de melhora pode ser equiparada a prática de tortura, que é vedada pelas normas constitucionais e legais já que tal sofrimento é desmoralizante desfazendo a posição humana.

Para Maria de Fátima Freire de Sá (2001 p. 67-68) existem dois elementos que estão envolvidos na eutanásia, sendo a intenção de realizar a eutanásia e efeito da ação.

Ainda explica que a intenção de realizar a Eutanásia pode gerar uma ação, daí tem-se "Eutanásia ativa", ou uma omissão, ou seja, a não-realização de ação que teria indicação terapêutica naquela circunstância - "Eutanásia Passiva” ou Ortotanásia (2001 p. 67-68). 
Assim, o agente pode cometer o ato de eutanásia tanto por ação, realizando o fato gerador que consuma a o ato, e por omissão, quando não realiza a ação médica que era necessária naquela situação.

\section{ARGUMENTOS CONTRÁRIOS À EUTANÁSIA}

Do mesmo modo, existem diversos argumentos contrários à pratica da eutanásia, se evidenciando as crenças religiosas e também razões políticas e sociais. Em muitas religiões a prática da eutanásia é vista como usurpação do direito à vida, pois somente Deus pode tirar a vida de alguém.

Assim, a vida no ponto de vista religioso é direito indisponível, não tendo permissão o ser humano para dispor sobre sua vida ou de outrem.

Consoante a isso, "mesmo tendo conhecimento das razões que levam o doente a pedir pela morte, é defendido acima de tudo o caráter sagrado da vida" (PINTO; SILVA, 2004, p. 37).

Se tratando do bem jurídico vida, destaca Cezar Roberto Bitencourt (2006 p. 2829)“que dentre os bens jurídicos de que o indivíduo é titular, a vida destaca-se como o mais valioso.A conservação da pessoa humana, que é a base de tudo, tem como primeira condição a vida"

Desse modo, não há um direito de disponibilidade sobre a própria vida, pois se leva em conta que o ser humano tem o direito à vida, e não o direito sobre a vida, não podendo assim dispor-se dela.

São inúmeros os autores que discordam da prática da eutanásia. Dentre eles, Maria Helena Diniz (1999, p. 250), que assevera que a eutanásia "não passa de um homicídio, em que, por piedade, há deliberação de antecipar a morte de doente irreversível ou terminal, a pedido seu ou de seus familiares, ante o fato da incurabilidade de sua moléstia..."

O consentimento dessa forma não teria validade para se opor ao direito à vida, até mesmo se considerando que a atual situação do enfermo, muitas vezes em estado de extrema vulnerabilidade diante da dor e sofrimento que está vivenciando, pode mascarar a sua real vontade. 
Igualmente, do ponto de vista legal, se configura crime, em princípio qualquer ato não natural de extinção da vida. A antecipação da morte que romperia o curso natural da vida caracterizaria o crime de homicídio, levando a uma imediata intervenção penal.

Conforme Moraes (2000, p. 91), “o direito à vida tem um conteúdo de proteção positiva que impede configurá-lo como o direito de liberdade que inclua o direito à própria morte”. Ou seja, pela constituição, temos o direito à vida e não o direito de extingui-la

Afirmam muitos outros doutrinadores que aceitar a legalização de uma norma tão controversa a fim decerta ação pretendida significaria admitir igualmente um conjunto sucessivo de outras normas que permitem uma série de outras ações originalmente consideradas imorais ou não pretendidas.

\section{CONSIDERAÇÕES FINAIS}

Muitas são as discussões que pairam sobre a eutanásia, sendo que ocorrendo ou não a liberação de tal prática, um princípio fundamental poderia estar na iminência de ser violado.

Em razão disso, diversas são as barreiras que se colocam à frente da legalização desse instituto, a exemplo das questões religiosas, jurídicas, morais, éticas que o tema engloba.

Sabe-se que a eutanásia é movida de legítimo sentimento de piedade e compaixão perante o sofrimento do outro assolado por alguma enfermidade, deste modo deve ser respeitada a vontade do paciente no estado que se encontra se este optar por se desfazer de sua própria vida, pois muitas vezes a vida que está levando nem mesmo mais pode ser considerada como "digna".

Contrário a esse entendimento, vimos que essa mesma vontade de se desfazer da própria vida pode ser uma vontade tomada por vicio, devido ao estado de fragilidade que o enfermo se encontra não podendo ser considerada uma vontade legitima.

Alguns autores declarados contra a prática da eutanásia argumentam que por vivermos em uma sociedade com diversas desigualdades sociais, a legalização da 
eutanásia, poderia desenvolver a descriminalização de pessoas mais humildes, os quais estão passiveis a sofrer restrições de tratamentos necessários.

$\mathrm{Na}$ área médica, a prática da eutanásia é um ponto contraditório, pois o exercício da medicina tem como escopo principal o ato de salvar vidas, trazer a cura, causar o alivio do sofrimento do doente. Já o objetivo da eutanásia é aliviar a dor do paciente, mas de outra maneira, a qual seria a morte.

Desse modo, é muito difícil indagar sobre o direito à morte, pois em nosso sistema jurídico o maior bem tutelado, é a vida, sendo que é de senso geral que esta deve ser indisponível. Não obstante, a morte deve ser encarada como parte do ciclo vital de todos como realmente é, a qual é uma condição que não se pode separar do ser humano.

Na visão do anteprojeto do Código Penal se o mesmo fosse aprovado, poderia existir uma insegurança popular, um desconforto na população, pois a liberdade que o médico teria no que diz respeito a decidir a possibilidade de fazer ou não fazer o procedimento gera insegurança, pois mesmo em estado terminal a vontade do paciente não é morrer.

Nesse sentido, a constituição Federal defende a vida desse modo proibindo qualquer disposição contraria a ela, gerando então o conflito entre o princípio da dignidade humana e o princípio da autonomia da vontade.

Embora seja um direito resguardado e garantido pelo Estado, o direito a vida não deve e não pode ser considerado um direito absoluto e supremo, sendo inteligente analisar casos específicos para que possa então decidir o melhor caminho a se seguir.

A vida humana não pode ser considerada apenas em seu meio biológico, tendo que se levar em consideração também a qualidade de vida da pessoa. A vida não se resume em estar vivo, pois a mesma possui uma dinâmica existencial, que dá ao ser humano meios que permitem a concretização de projetos existenciais de acordo com a sua

vontade.

Assim fica a pergunta de que a partir do momento em que o Estado impõe o prolongamento de uma vida não importa como, em um ponto onde a dignidade já se esvaiu, não estaria então desrespeitando a pessoa, seus direitos e sua dignidade? Responde-se, nesta senda, que um Estado Democrático de Direito, que consagrou a dignidade da pessoa humana como seu alicerce, não pode permitir que a pessoa doente 
seja mantida em condições consideradas desumanas e degradantes, prolongando-se artificialmente uma vida por meio de sofrimento físico e psíquico, aflições e humilhações.

Dessa forma, no momento em que não existe mais expectativa de cura e nem qualidade de vida para o enfermo é necessário que se evite o prolongamento desnecessário da vida, pois nesse cenário não existe mais benefícios mas sim malefícios sob pena de estar violando o direito a dignidade do paciente.

No caso dos pacientes que se encontram em estado terminal, assim como os que se encontram em estado vegetativo permanente ou em um coma que se mostra irreversível, a dignidade da pessoa humana, a autonomia da vontade, diante da situação concreta em que vivem esses enfermos terá um peso maior que o direito à vida, pois não seria possível nesse caso o reconhecimento do direito à morte digna sem que exista uma restrição ao direito a vida.

\section{REFERÊNCIAS}

ALEXY, Robert. Teoria dos direitos fundamentais. São Paulo: Malheiros Editores, 2008 .

BARROSO, Luís Roberto. A dignidade da pessoa humana no direito constitucional contemporâneo: a Construção de um Conceito Jurídico à Luz da Jurisprudência Mundial. $1^{a}$ reimpressão. Belo Horizonte: Fórum, 2013.

BITENCOURT, Cézar Roberto. Tratado de Direito penal - parte geral. 10. Ed. São Paulo: Saraiva 2006

BRASIL. Projeto de Lei do Senado ${ }^{\circ}$ 125, de 1996, disponível em: <https://www25.senado.leg.br/web/atividade/materias//materia/27928>. Acesso em $18 / 03 / 2019$

BRASIL.Projeto de Lei do Senado $\mathbf{n}^{\circ}$ 236, de 2012, disponível em: <https://www25.senado.leg.br/web/atividade/materias/-/materia/106404>. Acesso em 06/04/2019.

BORGES, Roxana Cardoso Brasileiro.Disponibilidade dos direitos de personalidade e autonomia privada; São Paulo; Saraiva 2007.

DINIZ, Maria Helena. Curso de Direito Civil Brasileiro: teoria das obrigações contratuais e extracontratuais. 27. ed. São Paulo: Saraiva 2011.

DINIZ. Maria Helena. O estado atual do biodireito. 3. ed. São Paulo: Saraiva, 2006. 
FRANCKE, A.L., et al. Nursing staff andeuthanasia in theNetherlands. A nationwidesurveyonattitudesandinvolvement in decisionmakingand the performance ofeuthanasia. Patienteducationandcounseling, v. 99, n. 5, 2016.

GOLDIM JOSÉ ROBERTO.Eutanásia. Disponívelem:

<http://www.ufrgs.br/bioetica/eutanasi.htm>. Acessoem: 01/04/2019.

GOLDIN, José Roberto. Caso TerriSchiavo; Retirada de Tratamento. Disponível em: https://www.ufrgs.br/bioetica/terri.htm. Acesso em 11/03/2019.

GONÇALVES, A. B. Eutanásia: Direito de matar ou direito de morrer? Âmbito Jurídico. Rio Grande, 14 mar. 2007. Disponível em: Acesso em: 03/04/2019.

GRIFFITHS, J; WEYERS, H. ADAMS, M. Euthanasiaand Law in Europe.Oregon: Hart Publishing, 2008.

JUNGES. José Roque. Bioética: perspectivas e desafios. São Leopoldo: Coleção Focus. Ed. Unisinos, 1999.

MALUF, Adriana Caldas do Rego Freitas Dabus. Curso de Bioética e Biodireito. 2. Ed. São Paulo: Atlas, 2013.

MIRABETE, Júlio Fabrini, Manual de Direito Penal, v. 2, 25. ed. São Paulo: Atlas, 2007.

MORAES, Alexandre de. Direitos Humanos Fundamentais. $3^{\text {a }}$ ed. São Paulo: Atlas, 2000 .

NICOL, J.; TIEDEMANN, M.; VALIQUET, D. EuthanasiaandAssisted Suicide: InternationalExperiences. Publication n ${ }^{\circ}$ 2011-67-E, 8 de abril de 2011 (revisada em 25 de outubro de 2013). Otawa: Library ofParliament, 2013.

PESSINI, Léo; BARCHIFONTAINE, Christian de Paul de. Fundamentos da Bioética. São Paulo: Paulus, 1996.

PINTO, Susana M. F.; SILVA, Moreira da; FLORIDO, A. C. A Incapacidade Física, Nursing. Lisboa. ISSN 0871- 6196: (Março 2004).

SILVA, José Afonso da. Curso de direito constitucional positivo. 30. ed. rev. e atual. São Paulo: MORAES, A. Constituição do Brasil Interpretada. São Paulo: Atlas, 2002.

SILVA, Sônia Maria Teixeira da. Eutanásia. Revista Jus Navigandi, ISSN 1518-4862, Teresina, ano 5, n. 48, 1 dez. 2000. Disponívelem: <https://jus.com.br/artigos/1863>; Acessoem:06/04/2019.

SMIES, J.T. LegalizationofEuthanasia in theNetherlands, The. Gonz. J. Int'l L., v. 7, p. i, 2003.

SZTAJN, Rachel. Autonomia privada e direito de morrer: eutanásia e suicídio assistido. São Paulo: Cultural Paulista - Universidade da Cidade de São Paulo, 2002. 
SÁ, Maria de Fátima, Direito de Morrer: eutanásia, suicídio assistido, Editora Del Rey, 2001.

TROYA, MaríaSosa.Idoso que ajudou esposa a morrer: "Os policiais diziam: teríamos feito o mesmo".Disponível

em:<https://brasil.elpais.com/brasil/2019/04/05/internacional/1554461402_394602.html ?id_externo_rsoc=FB_BR_CM\&hootPostID=3989c6c97e65eb9c00b1aa1cf70bd61b $>$. Acesso em: 8 abr. 2019 